\title{
NECESIDAD DE PROFUNDIZACIÓN DE LA COOPERACIÓN \\ JURISDICCIONAL INTERNACIONAL Y EL RECONOCIMIENTO DE LOS FALLOS EXTRANJEROS EN EL ÁMBITO INTERAMERICANO \\ NECESSIDADE DE APROFUNDAMENTO DA COOPERAÇÃO JURISDICIONAL INTERNACIONAL E O RECONHECIMENTO DOS FALHOS ESTRANGEIROS NO AMBITO INTERAMERICANO
}

Eduardo Tellechea Bergman

Resumen: El incremento contemporáneo de los litigios suscitados en torno a las relaciones privadas internacionales y consecuentemente de los casos de cooperación jurisdiccional internacional en sus distintos niveles o grados $y$ de reconocimiento de sentencias extranjeras, impone la necesidad de actualizar y profundizar las soluciones hoy vigentes a nivel continental con miras a una mejor realización transnacional de la justicia.

Resumo: O incremento contemporâneo dos litígios suscitados em torno às relações privadas internacionais y consequentemente dos casos da cooperação jurisdicional em seus distintos níveis o graus e de reconhecimento de sentencias estrangeiras impõe a necessidade de atualizar y profundir as soluções hoje vigentes a nível continental com miras a uma melhor realização transnacional da justiça.

Palabras clave: Cooperación jurisdiccional internacional, Reconocimiento de sentencias extranjeras, Jurisdicción internacional indirecta, Jurisdicción internacional exclusiva

Palavras-chave: Cooperação jurídica internacional, Reconhecimento das sentencias estrangeiras, Jurisdição internacional indireta, Jurisdição internacional exclusiva

* Universidad de la República, Uruguay.

E-mail: comitasgentiumhuber@gmail.com

Recibido: 16/06/2017. Aceptado: 01/09/2017. 


\section{INTRODUCCIÓN}

La cooperación jurisdiccional internacional, actividad procesal desplegada en un Estado al servicio de un proceso tramitado o a tramitarse en otro, tradicionalmente ha sido fundada en la reciprocidad, la conveniencia o la comitas gentium ${ }^{1}$, asentándose hoy en una práctica creciente entre las naciones que responde a la preocupación que la justicia no resulte frustrada por fronteras nacionales que se erijan en obstáculos a su realización ${ }^{2}$. En tal sentido Alcalá Zamora advertía hace más de medio siglo, con palabras que aún conservan plena vigencia: "el progreso incesante de los medios de comunicación y las cada día mayores relaciones mercantiles entre las naciones del mundo, son factores que contribuyen a fomentar y aún a exigir la cooperación entre los distintos Estados de la tierra" ${ }^{3}$. Los Principios de ASADIP sobre Acceso Transnacional a la Justicia (en adelante Principios de ASADIP), aprobados en su redacción actual en ocasión de las X Jornadas de ASADIP de Buenos Aires de noviembre de 2016, disponen coincidentemente en el Capítulo 4, "Cooperación interjurisdiccional", artículo 4.1, "La cooperación interjurisdiccional es un deber ineludible de los Estados, no solamente en la realización de actos de mero trámite como las notificaciones y citaciones, sino también en todos aquellos actos o medidas necesarias para la consecución de los fines del proceso, incluyendo la cooperación cautelar así como la identificación, conservación y producción de pruebas"4.

\footnotetext{
1 Noción que en su origen, en el siglo XVII, Ulrico Huber le atribuyera un sentido más profundo que el de mera cortesía internacional, fundándola en el interés común y la convención tácita entre las naciones. MEIJERS, Eduard Mauritz. "L'histoire des principes fondamentaux du droit international privé à partir de Moyen Age spécialement dans l'Europe occidentale. En: Recueil des Cours. Académie de Droit International. 1933, vol 49, III, p. 543-686.

2 TELLECHEA BERGMAN, Eduardo. "Dimensión judicial del caso privado internacional. Análisis de la cooperación de mero trámite, probatoria y cautelar en el ámbito interamericano y del Mercosur. En: XXXIV Curso de Derecho Internacional. Washington: Organización de Estados Americanos. Comité Jurídico Interamericano, 2007, p. 221-222. En conformidad, SENTÍS MELENDO, Santiago. "El auxilio entre jueces de distinta jurisdicción”. La Ley. 1956, $\mathrm{n}^{\circ}$ 48, p. 70. Ídem, MIAJA DE LA MUELA, Adolfo. Derecho Internacional Privado, 8a. ed. Madrid: ATLAS, 1978, p. 499 y ss.; ARAÚJO, Nadia de. Direito Internacional Privado - Teoria e Prática Brasileira, $3^{\mathrm{a}}$ ed. Rio de Janeiro: Renovar, 2006, p. 266-267; GASPAR, Renata Alvarez y KLEIN, Luciane. "La cooperación jurídica internacional en Brasil: especial referencia al diálogo entre el DIPr. autónomo y convencional y los derechos humanos". En: MORENO RODRÍGUEZ, José Antonio y MARQUES, Claudia Lima (ed.). Los servicios en el Derecho Internacional Privado. Jornadas de la ASADIP 2014. Porto Alegre - Asunción: Gráfica e Editora RJR, 2014, p. 191-217.

3 Palabras citadas por CAPPELLETTI, Mauro. "Riconoscimento delle sentenze straniere e basi idiologiche della interpretazione giuridica”. Boletín Mexicano de Derecho Comparado.1975, $\operatorname{vol} 3, n^{\circ} 22 / 23$, p.33.

4 En igual sentido, SCOTTI, Luciana. "El acceso a la justicia en el Derecho Internacional Privado argentino: nuevas perspectivas en el Código Civil y Comercial de la Nación”. En: El acceso a la justicia en el derecho internacional privado - Jornadas de ASADIP (2015, Asunción).
} 


\section{LAS SOLUCIONES CLÁSICAS}

El auxilio jurídico internacional alcanza importantes desarrollos en la región ya en la segunda mitad del siglo XIX.

El Tratado de Montevideo de Derecho Procesal Internacional de $1889^{5}$ en el Título III, "Del cumplimiento de los exhortos, sentencias y fallos arbitrales", prevé soluciones pioneras para la época, tales, las resultantes del artículo 5, que realiza una prolija enumeración de los requisitos que las sentencias extranjeras deben cumplir para su reconocimiento y del artículo 10 , que expresamente contempla los exhortos que "refieran a embargos"6, permitiendo de este modo el surgimiento de una jurisprudencia que en el caso de Uruguay, hizo posible un progresivo diligenciamiento de las solicitudes de cooperación cautelar rogadas por los tribunales de otros Estados Partes. El Tratado de Derecho Comercial Internacional de 1889 también legisló sobre asistencia cautelar internacional en el Título X, "De las falencias", artículos 37 y 38.

En el marco uruguayo - argentino la cooperación jurídica se afianza en los albores del siglo veinte con la firma en Montevideo, el 7.9.1903, del Convenio Ampliatorio del Tratado de Derecho Procesal Internacional de 1889, en vigor desde el 4.10.1907, por canje de instrumentos de ratificación efectuado en Buenos Aires. Acuerdo que adelanta soluciones que textos continentales y regionales recién acogerían décadas más tarde. Tales, la exclusión en el artículo 1 del requisito de la legalización para acreditar la autenticidad de los exhortos transmitidos vía diplomática o consular, exigido genéricamente por el artículo 3 del Tratado de 1889, y la consagración de la gratuidad en la tramitación de las rogatorias libradas de oficio, artículo 3. Gratuidad que recién sería recibida más de setenta años después por el Protocolo

\footnotetext{
5 El Tratado fue ratificado por Argentina, Bolivia, Paraguay, Perú y Uruguay; Colombia adhirió. Actualmente varias de sus disposiciones han sido sustituidas entre los Estados Partes por regulaciones posteriores. Argentina, Paraguay y Uruguay aprobaron el Tratado de Montevideo de Derecho Procesal Internacional de 1940 y posteriormente pasaron a ser Partes, al igual que Colombia y Perú, de las Convenciones Interamericanas de 1975 sobre Exhortos o Cartas Rogatorias y Recepción de Pruebas en el Extranjero y de 1979 sobre Cumplimiento de Medidas Cautelares y Eficacia Extraterritorial de las Sentencias y Laudos Arbitrales Extranjeros y el Protocolo Adicional a la Convención Interamericana sobre Exhortos o Cartas Rogatorias. Argentina y Uruguay también son Partes del Protocolo Adicional a la Convención Interamericana sobre Recepción de Pruebas en el Extranjero. Bolivia ratificó las Convenciones sobre Exhortos o Cartas Rogatorias y sobre Eficacia Extraterritorial de las Sentencias y Laudos Arbitrales Extranjeros. La cooperación judicial internacional y el reconocimiento de los fallos extranjeros entre Argentina, Brasil, Paraguay y Uruguay hoy se presta en aplicación de los Protocolos [del MERCOSUR] de Las Leñas sobre Cooperación y Asistencia Jurisdiccional Internacional, Decisión CMC 05/92 y de Ouro Preto de Medidas Cautelares, Decisión CMC 27/94.

6 Cabe recordar que en el Congreso de Montevideo de 1888-1889, el Miembro Informante, Dr. Gálvez, Delegado de Perú, al explicar el contenido del artículo 10 señaló expresamente: “en este artículo se estatuye que cuando los exhortos o cartas rogatorias contengan comisiones de trascendencia, como son las de practicar embargos...", Actas de los Tratados de Montevideo de 1889, p. 337.
} 
Adicional de Montevideo de 1979 a la Convención Interamericana de Panamá de 1975 sobre Exhortos o Cartas Rogatorias, artículo $5^{7}$.

El Tratado de Derecho Procesal Internacional de Montevideo de 1940, aprobado por Argentina, Paraguay y Uruguay, respecto a su precedente de 1889 , excluye a nivel multilateral la exigencia de la legalización en relación a las rogatorias transmitidas vía diplomática o consular, artículo 11, párrafo final; desarrolla la cooperación cautelar internacional, artículos 12 a 14, sólo contemplada de manera proteica por el anterior Tratado, constituyendo un valioso y directo antecedente de la Convención Interamericana de Montevideo de 1979 sobre Cumplimiento de Medidas Cautelares, legislando también sobre la materia en el Título IV, "Del concurso civil de acreedores", artículos 18 y 19; y prevé además procedimientos específicos aplicables tanto a la ejecución de las sentencias y fallos arbitrales extranjeros y a aquellos emanados de tribunales internacionales, artículo 7, cuanto a los casos en que se trate de hacer valer como prueba la autoridad de cosa juzgada del fallo foráneo, artículo 9. El Tratado de Derecho Comercial Terrestre de 1940, vigente entre los mismos países que el de Derecho Procesal, al igual que su similar de 1889, también contempla la cooperación cautelar internacional, Título VIII, "De las quiebras", en especial, artículos 43 y 44.

\section{REGULACIONES ACTUALES A NIVEL CONTINENTAL Y REGIONAL}

Pluralidad de variables intervinientes entre las que destacan el desarrollo de los medios de comunicación en sus distintas modalidades y una creciente flexibilización de las fronteras nacionales consecuencia de proceso de integración y de la globalización, más allá de dificultades puntuales, han coadyuvado en las últimas décadas a una acentuada internacionalización de la vida humana, ámbito en el que destaca el crecimiento cuasi exponencial registrado por las relaciones privadas internacionales 8 . Panorama determinante de un significativo incremento de litigios suscitados en torno a dichas relaciones y consecuentemente de casos de cooperación judicial intencional y reconocimiento de fallos extranjeros ${ }^{9}$, constituyendo dichas

\footnotetext{
7 El artículo 5 del Protocolo Adicional de Montevideo a la Convención Interamericana de 1975 sobre Exhortos o Cartas Rogatorias, así como el artículo 6 del Protocolo Adicional de La Paz a la Convención Interamericana de 1975 sobre Recepción de Pruebas en el Extranjero, supusieron un importante avance respecto a lo que preveían las referidas Convenciones que ponían las costas y demás gastos originados en el cumplimiento de las rogatorias a cargo de los interesados, respectivamente, artículos 12 y 7 . El principio de gratuidad en la tramitación de los exhortos es recibido con amplitud en el ámbito del Mercosur por el Protocolo de Las Leñas de Cooperación y Asistencia Jurisdiccional Internacional, Decisión CMC 05/992, artículo 15. 8 En coincidencia, FELDSTEIN DE CÁRDENAS, Sara L. Jurisdicción Internacional en Materia Contractual. Buenos Aires: Abeledo Perrot, 1995, p. 25 y ss.

9 TELLLECHEA BERGMAN, Eduardo. Derecho Internacional Privado. Montevideo: La Ley, 2010, p. 3 y 4; ídem, entre otros, SCOTTI Luciana B Op. cit., p. 213-214.
} 
cuestiones una de las áreas más relevantes del actual DIPr. ${ }^{10}$.

Consecuencia de dicha realidad, así como de desarrollos convencionales a nivel interamericano y regional, se constata actualmente entre Argentina, Brasil, Paraguay y Uruguay un notorio incremento de la cooperación judicial internacional regulada por las Convenciones Interamericanas vigentes en la materia y los Protocolos del Mercosur. Regulaciones entre las que corresponde resaltar, por su importancia, las Convenciones Interamericanas de Panamá de 1975 sobre Exhortos o Cartas Rogatoria y Recepción de Pruebas en el Extranjero y de Montevideo de 1979 sobre Cumplimiento de Medidas Cautelares y Eficacia Extraterritorial de las Sentencias y Laudos Arbitrales Extranjeros, cuyas soluciones son profundizadas en distintos aspectos por los acuerdos alcanzados en el Mercosur por los Protocolos de Las Leñas de Cooperación y Asistencia Jurisdiccional Internacional, Decisión CMC 05/92 y de Ouro Preto de Medidas Cautelares, Decisión CMC 27/94. Textos que procuraron atender necesidades emergentes del proceso de integración tomando en consideración lo previsto por las propias Convenciones Interamericanas ${ }^{11}$, lo que permitió asegurar entre los países de la zona la prestación del espectro total del auxilio jurisdiccional internacional ${ }^{12}$, pues a nivel interamericano Brasil es Estado Parte de las Convenciones sobre Exhortos o Cartas Rogatorias y Eficacia Extraterritorial de las Sentencias y Laudos Arbitrales Extranjeros, pero no de aquellas sobre Recepción de Pruebas en el Extranjero y Cumplimiento de Medidas Cautelares.

En Uruguay como consecuencia de la aplicación de las citadas regulaciones interamericanas y regionales, se transmiten actualmente a través de la Autoridad Central miles de exhortos al año con los países del área. Asistencia jurisdiccional internacional a la que corresponde añadir un volumen igualmente significativo proveniente de la aplicación del Código General del Proceso, en adelante CGP, que atiende en defecto de tratado o convención el auxilio jurisdiccional y el reconocimiento de los fallos extranjeros ${ }^{13}$, Libro Segundo, Título X, "Normas Procesales Internacionales", Capítulos: I. "Normas Generales"; II. "De la Cooperación Judicial Internacional"; III. "De la Cooperación

10 FERNÁNDEZ ARRROYO, Diego P. "Propuestas para una evolución deseable del problema de la competencia judicial internacional”. En: OYARZÁBAL, Mario J.A. (Ed.). Derecho procesal transnacional. Homenaje al Profesor Dr. Gualberto Lucas Sosa. Buenos Aires: Ed. Ábaco, 2012, p.142.

11 Convención Interamericana sobre Exhortos o Cartas Rogatorias, artículo 14, "Los Estados Partes que pertenezcan a sistemas de integración económica podrán acordar directamente entre sí procedimientos y trámites más expeditos que los previstos en esta Convención. Estos acuerdos podrán se extendidos a terceros Estados en la forma que resolvieren las partes"; ídem, Convención Interamericana sobre Cumplimiento de Medidas Cautelares, artículo 17.

12 Ver, TELLECHEA BERGMAN, Op. cit., p. 211- 260.

13 CGP, artículo 524, "Normas aplicables", "En defecto de tratado o convención, los tribunales de la República deberán dar cumplimiento a las normas contenidas en el presente Título". 
Judicial Internacional en Materia Cautelar"; y IV. "Del Reconocimiento y Ejecución de las Sentencias Extranjeras", artículos 524 a 543 ${ }^{14}$.

\section{DESARROLLOS PROPUESTOS}

El incremento contemporáneo a nivel interamericano de la asistencia jurisdiccional internacional en sus distintos niveles impone la actualización de las regulaciones vigentes, a través de posibles y necesarios desarrollos.

\subsection{Propuestas en materia de cooperación internacional de mero trámite y probatoria}

La experiencia resultante de la aplicación de las Convenciones Interamericanas sobre Exhortos o Cartas Rogatorias y Recepción de Pruebas en el Extranjero, ambas con alto número de Estados Partes, permite constatar la necesidad de perfeccionar y profundizar algunas de sus soluciones ${ }^{15}$, tales:

\subsubsection{Ampliación del ámbito material en el que los Estados se obligan a prestar cooperación}

Ambas Convenciones, artículos 2, sólo comprometen auxilio en materia civil y comercial, previendo la posibilidad que los Estados puedan formular declaraciones ampliando su alcance a lo laboral, contencioso administrativo y penal, Convención sobre Exhortos o Cartas Rogatorias, artículo 16; Convención sobre Recepción de Pruebas en el Extranjero, artículo 15. Opción que pocos países han ejercido, más allá que en la práctica algunos brinden asistencia jurisdiccional respecto a un elenco más extenso de temas. A nivel del Mercosur, el Protocolo de Las Leñas de Cooperación y Asistencia Jurisdiccional Internacional contempla la cooperación de mero trámite y probatoria de manera más amplia, pues sin necesidad de declaración de los Estados abarca además del ámbito civil y comercial, el laboral y el administrativo [contencioso administrativo], Capítulo IV,

\footnotetext{
14 Las disposiciones del Título, "Informe" de los autores del Proyecto del Título X, "Normas Procesales Internacionales", Profesores Doctores Opertti y Tellechea, a la Comisión Redactora del Código conformada por los Profesores Doctores Gelsi Vidart, Véscovi y Torello, buscaron asegurar un tratamiento homogéneo de la cooperación jurídica internacional y el reconocimiento de las sentencias extranjeras ante ausencia de regulaciones convencionales tomando en consideración y profundizando, en algunos casos, las soluciones consagradas a nivel interamericano, así, en materia de apreciación de la jurisdicción internacional como requisito para el reconocimiento del fallo extranjero, artículo 539.1.4.

$15 \mathrm{Al}$ respecto, TELLECHEA BERGMAN, Eduardo. "Desarrollos necesarios en el ámbito interamericano en materia de condición procesal del litigante extranjero y asistencia judicial internacional". En: Liber Amicorum Jürgen Samtleben. Avances del Derecho Internacional Privado en América Latina. Max Plank Institute Fur Ausländisches Und Internationales Privatecht. Montevideo: FCU, 2002.
} 
“Cooperación en Actividades de Mero Trámite y Probatorias", artículo 5.

La consolidación de la asistencia jurisdiccional internacional a nivel continental impone contemplar a texto expreso el compromiso de los Estados a brindar auxilio en el ámbito laboral y contencioso administrativo, así como prever su prestación en cuestiones de familia y minoridad, materias en las que sin perjuicio de ser atendida la cooperación internacional en aspectos puntuales por regulaciones convencionales específicas ${ }^{16}$, la complejidad y variedad de los casos vinculados a las mismas torna imprescindible asegurar su prestación de modo general.

\subsubsection{Propuestas referidas a la transmisión de exhortos}

a) Extensión explícita a la cooperación probatoria de las distintas vías previstas por la Convención Interamericana sobre Exhortoso Cartas Rogatorias

Mientras que la Convención sobre Exhortos o Cartas Rogatorias contempla las vías diplomática o consular, autoridad central, judicial y particular, artículo 4, a las que añade la comunicación directa entre jueces de frontera, artículo 7, la Convención sobre Recepción de Pruebas en el Extranjero, artículo 11, sólo prevé los procedimientos diplomático o consular, autoridad central y judicial. Vías que entre los Estados Partes de ambas Convenciones corresponde ampliar a todas las demás enumeradas por la Convención sobre Exhortos, cuanto que la de Recepción de Pruebas en el artículo 14 dispone:

Esta Convención no restringirá las disposiciones de convenciones que en materia de exhortos o cartas rogatorias sobre la recepción u obtención de pruebas hubieran sido suscriptas o se suscribieren en el futuro en forma bilateral o multilateral entre los Estados Partes, o las prácticas más favorables que dichos Estados pudieran observar en la materia.

Y, precisamente, la Convención de Exhortos en el artículo 2.b, salvo reserva al respeto, comprende la recepción y obtención de pruebas y todos los Estados Partes de la Convención de Exhortos ${ }^{17}$ lo son también de la de Recepción de Pruebas.

b) Recepción de diferentes vías para la transmisión de exhortos en el ámbito del Mercosur

16 Tales, las Convenciones Interamericanas de Montevideo de 1989 sobre Obligaciones Alimentarias y sobre Restitución Internacional de Menores.

17 Excepto República Dominicana, que es Parte de la Convención sobre Recepción de Pruebas en el Extranjero pero no de la de Exhortos o Cartas Rogatorias. 
El Protocolo de Las Leñas sobre Cooperación y Asistencia Jurisdiccional Internacional si bien únicamente refiere a la autoridad central, artículos 2 y 5, con finalidad de ponerla en efectivo funcionamiento en la región, pues al momento de su aprobación sólo operaba en Argentina y Uruguay, en puridad no excluye las demás vías previstas por la Convención Interamericana sobre Exhortos o Cartas Rogatorias de la que son Partes los cuatro Estados que han ratificado el Protocolo, por lo que corresponde concluir en la pertinencia de las mismas. En tal sentido el artículo 35 del texto de Las Leñas dispone: "El presente Protocolo no restringirá las disposiciones de las convenciones que sobre la misma materia hubieran sido suscriptas anteriormente entre los mismos Estados en tanto no lo contradigan", y la posibilidad de empleo de pluralidad de medios para la transmisión de las solicitudes de auxilio internacional no sólo no contradice, sino que se inscribe en los objetivos enunciados por el Preámbulo del Protocolo: "promover e intensificar la cooperación" a través de "la adopción de instrumentos comunes que consoliden la seguridad jurídica". En coincidencia, la Enmienda al Protocolo de Cooperación y Asistencia Jurisdiccional Internacional en Materia Civil, Comercial, Laboral y Administrativa entre los Estados Partes del Mercosur, Decisión CMC 07/02 ${ }^{18}$ y el Acuerdo [espejo] de Cooperación y Asistencia Jurisdiccional en Materia Civil, Comercial, Laboral y Administrativa entre los Estados Partes del Mercosur y la República de Bolivia y la República de Chile, Decisión CMC 08/02 ${ }^{19}$, expresamente admiten la multiplicidad de vías y en relación a la aplicación de disposiciones contenidas en anteriores convenciones establecen con mayor precisión que el texto que les precediera, artículo 35, "El presente acuerdo no restringirá las disposiciones de las convenciones que sobre la misma materia hubieren sido suscriptas anteriormente entre los Estados Partes, en tanto sean más beneficiosas para la cooperación". Asimismo debe tenerse presente que el Protocolo de Ouro Preto de Medidas Cautelares, Decisión CMC 27/94, artículo 19, vigente entre Argentina, Brasil, Paraguay y Uruguay, consagra con amplitud distintos procedimientos para la transmisión de rogatorias en un nivel de asistencia sensiblemente más complejo como es el cautelar y contempla, inclusive, la posibilidad de comunicación directa entre jueces de zonas de frontera, párrafo cuarto del artículo 9, por lo que no existe razón lógica para excluir la aplicación de estos modos respecto a auxilios de menor grado. La interpretación propuesta, favorable a la prestación de la asistencia jurisdiccional internacional así como a asegurar la realización de la justicia más allá de los límites de los Estados, es coincidente con la posición a la que arribaran las doctrinas

18 La Enmienda ha sido aprobada por Argentina, Brasil y Paraguay, no estando aún vigente. 19 El Acuerdo se encuentra vigente entre Argentina, Brasil, Paraguay, Chile y Ecuador, que adhirió el 30.6.2002. 
de Argentina y Uruguay $^{20}$ en ocasión del XXV Congreso Argentino de Derecho Internacional, Sección de Derecho Internacional Privado, La Plata 26 y 27 de septiembre de 2013, que abordara el tema a partir de valioso relato de la Profesora Dra. María Blanca Noodt Taquela, referido a la "Aplicación de la norma más favorable a la cooperación judicial internacional", concluyendo por unanimidad: "1.2. En caso de pluralidad de fuentes en principio aplicables y sin perjuicio de las normas de compatibilidad del derecho de los tratados en lo que fueren pertinentes, se deberá aplicar la norma más favorable a la cooperación judicial internacional" y "1.3. En particular la cooperación puede prestarse con el recurso a normas de distintas fuentes con arreglo a los métodos del Derecho Internacional Privado y a principios generales aceptados en la materia". Conceptos acogidos por los Principios de ASADIP, que en el Capítulo 1, "Disposiciones y principios generales", artículo1.2, consagran el aforismo in dubio pro cooperationis, agregando que "los operadores jurídicos deben orientarse al favorecimiento de la cooperación jurídica internacional".

El interés de facilitar la cooperación jurídica internacional torna conveniente legislar de manera explícita la pertinencia de la multiplicidad de vías para la transmisión de las rogatorias, evitando de este modo tener que recurrir a interpretaciones más o menos complejas para permitir al justiciable optar por uno u otro medio.

\section{c) Propuestas atinentes a vías específicas de transmisión de los exhortos}

\section{c.1) Propuestas referidas a la vía autoridad central}

Las autoridades centrales en tanto organismos especializados en DIPr. y cooperación jurisdiccional internacional, transmiten actualmente la mayoría de los exhortos entre los países de la región, superando de este modo el encadenamiento burocrático, cuasi kafkiano, resultante de la vía diplomática o consular. Vía que con frecuencia ha supuesto un serio obstáculo a la realización de la justicia, pues su complejo funcionamiento insume usualmente varios meses.

Las autoridades centrales, previstas por las Convenciones de La Haya de 1965 sobre la Notificación o Traslado en el Extranjero de Documentos Judiciales o Extrajudiciales en Materia Civil o Comercial y de 1970 sobre la Obtención de Pruebas en el Extranjero en Materia Civil o Comercial, son recibidas a nivel interamericano a partir de las

20 En el Congreso de la Asociación Argentina de Derecho Internacional y en las Jornadas Rioplatenses de Derecho Internacional Privado celebradas en la Plata el 25.9.2013, que lo precedieran, participaron por Uruguay además del autor, los colegas Profs. Drs. Didier Opertti y Cecilia Fresnedo de Aguirre. 
Convenciones de 1975 de Panamá sobre Exhortos o Cartas Rogatorias, artículo 4 y Recepción de Pruebas en el Extranjero, artículo 11 y más tarde, por las Convenciones de 1979 de Montevideo Cumplimiento de Medidas Cautelares, artículo 13 y de 1989 sobre Restitución Internacional de Menores, artículo 7. El Protocolo de Las Leñas de Cooperación y Asistencia Jurisdiccional Internacional las organiza en el Capítulo II, "Autoridades Centrales", artículo 2.

El actual funcionamiento de las autoridades centrales en los países de la región no debe suponer, empero, un obstáculo para que su actuación sea optimizada, ni a la posibilidad de utilizar otros medios igualmente idóneos para la transmisión de los pedidos de asistencia jurídica internacional.

Entre las propuestas tendientes a dinamizar y profundizar las autoridades centrales cabe mencionar:

\section{c.1.1) Empleo de medios electrónicos}

La puesta en funcionamiento de las autoridades centrales ha permitido acelerar significativamente el auxilio judicial internacional, pero la transmisión de las rogatorias al ser realizada a través del medio postal, generalmente correo certificado, requiere en los hechos un lapso de varios días para el envío del exhorto desde la autoridad central rogante a la rogada. La celeridad en la realización de la justicia impone analizar la posibilidad del uso de medios electrónicos tanto para la transmisión de los exhortos, cuanto para otras comunicaciones entre las autoridades centrales referidas al cumplimiento de los mismos. Posibilidad que cuando estos organismos fueran creados en los años sesenta y setenta del siglo veinte por las Convenciones de La Haya e Interamericanas no era previsible, pero que hoy constituye una realidad que permite a través de actuales tecnologías una comunicación instantánea y segura, capaz de acreditar la autenticidad del pedido. Al respecto cabe recordar que en el Mercosur el Protocolo de San Luis de Asistencia Jurídica Mutua en Asuntos Penales, Decisión CMC 02/96, artículo 6.2, solución ya aplicada entre Brasil y Uruguay, contempla que las solicitudes de cooperación puedan ser transmitidas "por télex, facsímil, correo electrónico o similares", debiendo ser confirmadas por documento original firmado por la autoridad requirente dentro de los diez días siguientes a su expedición. Los Principios de ASADIP, Capítulo 4, "Cooperación interjurisdiccional", artículo 4.7, disponen al respecto:

En los actos de cooperación jurídica internacional, los jueces y demás operarios de justicia procurarán y favorecerán el uso de nuevas tecnologías de información y comunicación a su disposición, tales como comunicaciones telefónicas y videoconferencias, mensajes electrónicos 
y cualquier otro medio disponible, siempre que se garantice la seguridad de las comunicaciones.

El Protocolo Iberoamericano de Cooperación Jurídica Internacional ${ }^{21}$, aprobado por la XVII Cumbre Judicial Iberoamericana ${ }^{22}$ de Santiago de Chile de 2014, también contempla favorablemente el uso de los medios electrónicos al enunciar los "Principios Básicos en Materia de Cooperación Judicial Internacional”, numeral 6.

\section{c.1.2) Puesta en funcionamiento de procedimientos que permitan fluida comunicación de las autoridades centrales con los tribunales y que eviten injerencias de la administración en la tramitación de las rogatorias}

En aquellos ordenamientos en los que no esté prevista la comunicación directa entre las autoridades centrales y los tribunales del Estado al que pertenezcan en todo lo relativo a la recepción, transmisión de los pedidos de auxilio internacional y diligenciamiento de los mismos, ha de resultar conveniente posibilitar dicha comunicación eliminando la intermediación de otros organismos, lo que habrá de permitir un significativo acortamiento del tiempo que insume la tramitación de la asistencia.

En lo referido a evitar posibles interferencias de la administración en la prestación del acto cooperativo, resulta de interés lo dispuesto en el sistema judicial uruguayo por la Acordada 7134/92 de la Suprema Corte de Justicia, que a efectos de la determinación del turno de las sedes intervinientes en los trámites de los exhortos recibidos del extranjero toma en consideración la fecha de libramiento de éstos, evitando así toda manipulación al respecto y con tal finalidad la Suprema Corte aprueba anualmente una Planilla de Turnos referida al diligenciamiento de las rogatorias extranjeras. Con propósitos similares en cuanto a evitar injerencias en la tramitación de los exhortos, la Sección de Derecho Internacional Privado de la Asociación Argentina de Derecho Internacional recomendó en el XXV Congreso Argentino de Derecho Internacional, Conclusión 2.3: "Asegurar en el mayor grado posible la independencia técnica de la autoridad central".

\section{c.1.3) Tecnificación}

La compleja actividad a cargo de las autoridades centrales hace necesario capacitar a sus funcionarios en los distintos niveles y modalidades

21 El Protocolo fue declarado con valor de Acordada por la Suprema Corte de Justicia de Uruguay, Acordada 7815 de 20.8.2014.

22 La Cumbre Judicial Iberoamericana está constituida por los Presidentes de las Cortes y Tribunales Supremos de Justicia de los Estados de la Comunidad Iberoamericana de Naciones y los máximos responsables de los Consejos de la Judicatura. 
de la asistencia jurisdiccional internacional. A tales efectos habrá de resultar conveniente al prever su funcionamiento en futuros textos atender la realización de encuentros periódicos entre autoridades centrales del continente con tal finalidad, así como para intentar homogeneizar sus actuaciones a través de la elaboración de guías de buenas prácticas.

\section{c.1.4) Evaluar en los Estados en que fuera necesario por razones de extensión, la posible descentralización territorial de las autoridades centrales}

Se persigue a través de esta iniciativa dotar al funcionamiento de las autoridades centrales de mayor agilidad y vinculación con el medio en el que actúan y con las necesidades de los justiciables y los operadores de la justicia. En coincidencia, Conclusión 2.2, emanada de la Sección de Derecho Internacional Privado de la Asociación Argentina de Derecho Internacional en el antes mencionado XXV Congreso.

\section{c.2) Propuestas referidas a otras vías de transmisión de exhortos}

Por las opciones que ofrecen a la prestación de una eficiente asistencia jurídica, resulta de interés analizar posibles desarrollos atinentes a la vía particular y a la comunicación directa entre jueces fronterizos.

\section{c.2.1) Vía particular}

En esta modalidad el interesado retira la rogatoria de la sede exhortante y la remite a un corresponsal en el Estado rogado que de conformidad con la normativa de éste se encargará de hacerla llegar al tribunal competente para su diligenciamiento, por lo que se trata de un procedimiento que permite una transmisión rápida y reservada de las solicitudes de auxilio judicial.

El funcionamiento de esta vía se ve afectado en la práctica en razón que la misma, por su propia naturaleza, exige acreditar la autenticidad del exhorto foráneo. Acreditación que entre Estados no Partes de la Convención de La Haya de 5.10.1961 sobre Supresión de la Exigencia de Legalización de los Documentos Públicos Extranjeros ${ }^{23}$ requiere de la legalización, con todas las demoras que ello supone. ${ }^{24}$ Por

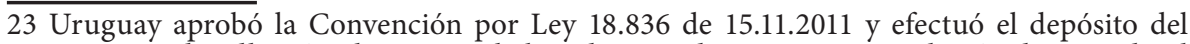
instrumento de adhesión el 9.2.2012, habiendo entrado en vigor para el país, de acuerdo al procedimiento previsto en el artículo 12, el 14.10.2012.

24 La legalización es requerida en relación a la vía particular, entre otras, por la Convención Interamericana sobre Exhortos o Cartas Rogatorias, artículos 5. a y 6, examinados en su conjunto; ídem, Convención Interamericana sobre Recepción de Pruebas en el Extranjero, 
lo que ha de resultar conveniente para un más eficaz funcionamiento de la modalidad, impulsar que los países americanos que aún no lo hubieren hecho, aprueben la Convención y que una futura revisión del marco regulatorio interamericano contemple que entre Estados Partes de convenios que como el de La Haya prevean procedimientos más expeditos de acreditación de la autenticidad de los documentos extranjeros, se estará a los mismos.

\section{c.2.2) Comunicación directa entre jueces fronterizos}

Distintos convenios prevén esta vía en relación a la cual es excluido el requisito de la legalización. Tales, las Convenciones Interamericanas sobres Exhortos o Cartas Rogatorias, artículo 7 y sobre Tráfico Internacional de Menores, artículo 15 y Protocolo de Ouro Preto de Medidas Cautelares, artículo 19, párrafo cuarto. Esta modalidad de comunicación jurisdiccional se adecua a la realidad de las zonas de frontera, en las que el entorno sociológico favorece el surgimiento de relaciones privadas internacionales de todo tipo y de litigios suscitados en torno a las mismas y consecuentemente hace necesario atender un significativo volumen de cooperación internacional entre jueces muy próximos entre sí.

En la frontera argentino - uruguaya sobre el Río Uruguay ha comenzado a tener exitosa aplicación este tipo de comunicación judicial, inclusive en materia cautelar. Situación que no ocurre, lamentablemente, en la frontera con Brasil, país que en base a una interpretación de su jurisprudencia de la exigencia de su Constitución referida a que las rogatorias deben estar sujetas a un contralor centralizado, exequatur, ante el Superior Tribunal de Justicia ${ }^{25}$, rechaza la posibilidad de remisión directa de exhortos entre jueces de zonas de frontera, aun cuando el tema, en puridad, refiere a la transmisión de las rogatorias y no a su control. Esta posición genera serias demoras que con frecuencia frustran la asistencia jurisdiccional y la propia realización de la justicia, cuanto que, vr. gr., un exhorto librado por un juez uruguayo de la ciudad fronteriza de Rivera a su homólogo de la contigua ciudad de Livramento, tiene que ser remitido a Montevideo para que la autoridad central de Uruguay lo envíe a la autoridad central en Brasilia para que ésta a su vez lo haga

artículos 10.1 y 13; Protocolo de Ouro Preto de Medidas Cautelares, artículo 19, párrafo tercero; Enmienda (no vigente), al Protocolo de Cooperación y Asistencia Jurisdiccional entre los Estados del Mercosur, Decisión CMC 07/02, artículo 10, párrafo tercero. En la normativa de fuente nacional uruguaya, el CGP, Libro Segundo, Título X, "Normas Procesales Internacionales", Capítulo II, "De la Cooperación Judicial Internacional”, artículo 527, "Exhortos o cartas rogatorias", numerales 1 y 2, consagra igual solución; en el mismo sentido, Decreto - Ley 15441 de 1.8.1983, "Se establecen normas para legalizar documentos extranjeros", artículos 1 y 5 .

25 Enmienda Constitucional 45 de 2004. Con anterioridad el contralor también era realizado de manera centralizada por el Supremo Tribunal Federal. 
llegar al Superior Tribunal de Justicia, que efectuado el control ha de remitirlo al Juzgado de Livramento para su diligenciamiento, que luego lo devolverá a través del mismo camino.

Un correcto funcionamiento de esta vía, hasta ahora subutilizada, ha de permitir una eficaz asistencia jurisdiccional en las fronteras. Propuesta que resulta coincidente con las "Recomendaciones a los Estados Americanos para la integración fronteriza o vecinal", adoptada por el Comité Jurídico Interamericano el 13.3.2014, en su 84 período ordinario de sesiones, CJI/RES.206 (L XXXIV-0/14). Al respecto cabe señalar que por Acordada no. 7885 de 21 de diciembre de 2016, la Suprema Corte de Justicia de Uruguay, resolvió designar "Juzgados de Frontera" a los efectos de la tramitación de las solicitudes de cooperación judicial internacional, a los Juzgados limítrofes con la República Argentina de los Departamentos de Artigas, Salto Paysandú, Río Negro, Soriano y Colonia, entrando a regir la presente Acordada para las comunicaciones cursadas a partir del primero de abril de 2017.

\subsection{Propuestas en materia de cooperación cautelar internacional}

Las medidas cautelares, providencias cuya finalidad es prevenir el daño resultante del retardo de una decisión jurisdiccional definitiva asegurando la eficacia de la misma, abarcan todas aquellas providencias dispuestas por los tribunales con el objeto de impedir actos de disposición o administración capaces de hacer ilusorio el resultado de un juicio ${ }^{26}$.

En el ámbito del auxilio jurisdiccional internacional la cooperación cautelar constituye un nivel de asistencia de singular complejidad y creciente planteo, destinado a evitar que la sentencia extranjera al igual que "los guardias de la ópera bufa", al decir de Calamandrei ${ }^{27}$, llegue demasiado tarde, cuando ya no existan posibilidades de hacerla efectiva $^{28,29}$.

26 En conformidad, FAIRÉN GUILLEN, Víctor. Teoría del Ordenamiento Procesal. Madrid: Tecnos, 1969, tomo 2, p. 899.

27 CALAMANDREI, Piero. Introduzione allo studio sistematico dei provedimento cautelare. Padova: CEDAM, 1936, p.144.

28 En similar sentido, COUTURE, Eduardo. "Los Embargos y el Tratado de Montevideo", nota de jurisprudencia, Revista de Derecho, Jurisprudencia y Administración, 1939, t. XXXVII, p. 247, reflexionaba: “¿en qué sentido influye sobre este fenómeno [las medidas cautelares] la circunstancia de que los bienes que son objeto de garantías se hallen en el extranjero? Ni lógica ni moralmente puede influir en ninguno. Más aún, se puede decir que una vez que el Derecho Internacional ha llegado al punto de fijar criterios de competencia entre los Estados, la extensión de la potestad coercitiva hacia bienes radicados en otro territorio resulta absolutamente indispensable".

29 En materia de cooperación cautelar internacional con especial referencia al ámbito regional y al DIPr. uruguayo, ver, OPERTTI BADAN, Didier. Exhortos y Embargos de Bienes Extranjeros. Medios de Cooperación Judicial Internacional, Montevideo: Ediciones Jurídicas Amalio Fernández, 1976; TELECHEA BERGMAN, Op. cit., p. 47-68; VESCOVI, Eduardo. 
Una medida cautelar adquiere cualidad internacional cuando adoptada por los tribunales del Estado con jurisdicción para conocer en el litigio cuyo resultado la cautela asegura, está destinada a cumplirse en otro. Ello sin perjuicio de medidas cautelares de urgencia, destinadas a asegurar el resultado de un juicio incoado o a incoarse en otro país, ordenadas por los magistrados del Estado de situación de los bienes o la persona a asegurar ${ }^{30}$, pues, como señalara Opertti en ocasión de analizar el tema en la CIDIP II, "cuando hay un bien jurídico a proteger en el territorio de determinado juez, éste podrá adoptar esa medida en base al principio de la jurisdicción más próxima, sin mengua del principio de la competencia internacional, devolviendo el resultado obtenido al juez natural internacional"31. El tribunal que conoce del cumplimiento de una sentencia extranjera también puede ordenar por sí medidas de seguridad, las que en definitiva poseen naturaleza cautelar internacional, cuanto su finalidad está dirigida a asegurar la eficacia de un fallo dictado fuera de frontera. Así lo dispuesto por la Convención Interamericana sobre Cumplimiento de Medidas Cautelares, artículo 7; el Protocolo del Mercosur de Medidas Cautelares, artículo 11, "Cooperación Cautelar en la Ejecución de Sentencia”; y a nivel de normas uruguayas de fuente nacional, el CGP, artículo 533, "Medidas previas a la ejecución". Disposiciones que reconocen como precedente lo dispuesto por el artículo 8 del Tratado de Montevideo de Derecho Procesal Internacional de 1940.

A nivel interamericano y del MERCOSUR la asistencia cautelar internacional es atendida por la Convención Interamericana de Montevideo sobre Cumplimiento de Medidas Cautelares y el Protocolo de Ouro Preto de Medidas Cautelares que tiene como antecedente aquella y respondió a la necesidad de incluir en este nivel de cooperación a Brasil en tanto Estado no Parte del texto continental. Ambas regulaciones tratan acerca de la aplicación de las leyes y la competencia de los tribunales del Estado requirente y requerido, la oposición de tercerías de mejor derecho y de dominio o de otros derechos reales, y legislan de manera detallada tipos especiales de cooperación cautelar, entre ellos, los referidos a la cooperación cautelar en instancia de cumplimiento de sentencias extranjeras, Convención, artículo 7, Protocolo artículo 11, y a la custodia de menores, Convención, artículo 9, Protocolo

Derecho Procesal Internacional. Uruguay, el Mercosur y América. Montevideo: Ediciones IDEA, 2000, p. 131-149; FRESNEDO DE AGUIRRE, Cecilia. "Cooperación jurisdiccional internacional cautelar. Dificultades que presenta en la práctica. Una mirada desde Uruguay". En: Taller Participativo. Dificultades metodológicas del discurso del Derecho Internacional Privado. Cómo superarlas y hacerlo más accesible. Buenos Aires: Universidad de Belgrano, The University of Ediburg, Universidad de Buenos Aires, British Academy, 2004.

30 Convención Interamericana de Montevideo de 1979 sobre Cumplimiento de Medidas Cautelares, artículo 10.

31 OPERTTI BADÁN, Didier. Exposición en Tercera Sesión. Comisión I - CIDIP II. Actas y Documentos Segunda Conferencia Especializada Interamericana sobre Derecho Internacional Privado. (CIDIP II), vol. II, Washington D.C.: Organización de Estados Americanos, 1980, p. 52-53. 
artículo 12; y además la Convención Interamericana consagra la denominada cooperación cautelar de urgencia por la jurisdicción más próxima, artículo 10 . Tipo de asistencia no contemplada por el texto del MERCOSUR, en razón de dificultadas invocadas por Brasil para aceptar esta modalidad en momentos en que recién abría sus tribunales al auxilio cautelar ${ }^{32}$.

No obstante la trascendencia de la cooperación cautelar para la configuración de un sistema integral de asistencia jurídica internacional en tanto el efectivo funcionamiento de este nivel incide directamente en la eficacia del reconocimiento de la sentencia extranjera, la Convención Interamericana ha sido ratificada por un reducido elenco de Estados: Argentina, Colombia, Ecuador, Guatemala, Perú, Paraguay y Uruguay. Realidad que a treinta y cinco años de aprobada la Convención impone abordar su reexamen.

En relación a una necesaria actualización de la cooperación cautelar internacional a nivel interamericano será de interés procurar:

\subsubsection{Regulación adecuada de la cooperación cautelar preparatoria}

Este tipo de asistencia es prevista sólo de manera escueta por el artículo 1 del texto interamericano cuando dispone: "Para efectos de esta Convención las expresiones "medidas cautelares..." se utilizan para indicar todo procedimiento o medio que tienda a garantizar los resultados o efectos de un proceso actual o futuro.... Por el contrario, el Protocolo de Ouro Preto si bien inicialmente también refiere de modo somero a las "medidas cautelares preparatorias", artículo 3, atiende luego de manera detallada las mismas en los artículos 13, que contempla que la interposición de la demanda en el proceso principal fuera de los plazos previstos para hacerlo en la legislación del Estado requirente "producirá la plena ineficacia de la medida cautelar preparatoria concedida” y 14, que exige que el tribunal exhortante al transmitir la rogatoria comunique al requerido el plazo contado a partir del cumplimiento de la cautela en el que la demanda deberá ser presentada en el proceso principal y a la mayor brevedad, la fecha de presentación de la misma o el transcurso del plazo establecido por la legislación del exhortante sin que tal interposición hubiere ocurrido. Asimismo y a fin que comience a computarse el término referido, el artículo 15 dispone que la sede

32 Entre Argentina, Paraguay y Uruguay, Partes de la Convención sobre Cumplimiento de Medidas Cautelares, el auxilio cautelar de urgencia se presta en base a lo dispuesto por la misma. Solución confirmada por el propio texto del Protocolo, artículo 26 [de iniciativa de las Delegaciones de Uruguay y Argentina], que dispone: "Este Protocolo no restringirá la aplicación de disposiciones más favorables para la cooperación contenidas en otras convenciones sobre medidas cautelares en vigor con carácter bilateral o multilateral entre los Estados Parte". 
rogada comunique de inmediato a la rogante la fecha en la que dio cumplimiento a la medida solicitada y en su defecto, las razones por las cuales ésta no fue cumplida. Obligación de explicar el incumplimiento de la cooperación ya recibida a nivel interamericano en materia de asistencia probatoria por el Protocolo de 1984 a la Convención sobre Recepción de Pruebas en el Extranjero, artículo 3, párrafo segundo, y que por su utilidad a la efectiva prestación del auxilio, juzgamos de interés extender en el ámbito continental respecto a la asistencia cautelar.

\subsubsection{Posibilidad que los tribunales arbitrales puedan requerir por sí cooperación cautelar}

Se trata de una competencia sobre la que entendemos pertinente reflexionar en el contexto interamericano, cuanto que se encuentra consagrada a nivel regional por los Acuerdos sobre Arbitraje Comercial Internacional entre los Estados Parte del Mercosur y entre los Estados Parte del Mercosur con la República de Bolivia y la República de Chile, respectivamente Decisiones CMC 03/98 y 04/98, artículo 19, párrafo cuarto de ambos textos ${ }^{33}$, que contemplan inclusive que los Estados puedan autorizar a tribunales arbitrales a remitir directamente solicitudes de asistencia cautelar vía autoridad central a las autoridades jurisdiccionales de las otras Partes.

\subsubsection{Supresión de la opción que la Convención Interamericana confiere a los Estados de limitar el alcance de la asistencia}

Posibilidad restrictiva del alcance convencional prevista por el artículo 1, parte final, inconveniente a los fines de asegurar una homogénea y eficiente asistencia internacional, no admitida por el Protocolo de Medidas Cautelares que consagra una cooperación no sujeta a tales límites.

\subsubsection{Comunicación directa entre jueces de frontera.}

Se considera de interés atento a la índole y necesidades de las zonas de frontera incluir la comunicación directa en la materia entre jueces fronterizos, opción no contemplada entre las vías enumeradas por el artículo 13 de la Convención y que el Protocolo de Ouro Preto, artículo 19, párrafo cuarto, consagró expresamente. A nivel interamericano la comunicación jurisdiccional fronteriza directa sin necesidad de legalización es acogida en relación a la asistencia de mero trámite y probatoria por la Convención sobre Exhortos o Cartas Rogatorias y de

33 El Acuerdo del Mercosur ha sido aprobado por Argentina, Brasil, Paraguay y Uruguay, Ley 17.834 de 23.9.2004; el Acuerdo Mercosur y Estados Asociados, aún no vigente, ha sido aprobado por Uruguay por Ley 17.751 de 26.3.2004. 
manera amplia, por la Convención de México de 1994 sobre Tráfico Internacional de Menores, artículo 15.

\subsubsection{Supresión de la legalización como requisito de alcance general}

La Convención sobre Cumplimiento de Medidas Cautelares, artículo 14.a, trata la condición de manera genérica, no excluyendo expresamente de la misma la transmisión de exhortos vías diplomática, consular y autoridad central, modos que por su calidad de oficiales, doctrina y derecho positivo coinciden en no requerir la exigencia. Tal lo dispuesto por el Tratado de Derecho Procesal Internacional de Montevideo de 1940 respecto a la transmisión de exhortos a través de agentes diplomáticos o consulares, artículo 11, parte final, y de modo más amplio, incluyendo la vía autoridad central y la comunicación directa entre jueces de frontera, por la Convención Interamericana de 1975 sobre Exhortos o Cartas Rogatorias artículos 6 y $7^{34}$. La disposición convencional en su redacción actual lleva a que en la práctica algunos países exijan la legalización para acreditar la autenticidad de las solicitudes de auxilio cautelar, cualquiera que fuere la vía empleada, cuando sólo correspondería requerir la condición en los casos de transmisión vía particular y ello, siempre que entre el Estado de origen de la solicitud y el rogado no exista una regulación convencional que como la Convención de la Haya de 5.10.1961 sobre Supresión de la Legalización consagre un procedimiento más expedito a los efectos.

\subsection{Propuestas en materia de reconocimiento de fallos extranjeros}

La coexistencia de pluralidad de ordenamientos jurídicos, presupuesto del Derecho Internacional Privado, impone solidaridad entre los Estados y universalidad en la justicia y, por consiguiente, corresponde reconocer, dadas ciertas condiciones, las resoluciones jurisdiccionales dictadas en el extranjero con miras a hacer efectiva la seguridad jurídica y el comercium internacional, evitando que las personas puedan quedar sujetas a decisiones jurisdiccionales contradictorias sobre un mismo asunto dictadas en distintos países. Como precisara Opertti,

...un sentimiento elemental de justicia, señala que las decisiones dictadas por los jueces de un Estado no deben quedar reducidas a su

34 La Convención Interamericana sobre Recepción de Pruebas en el Extranjero, artículo 13, también excluye la legalización cuando los exhortos sean transmitidos vía consular o diplomática o por conducto de las autoridades centrales. 
ámbito territorial cuando en él no obtienen el acatamiento voluntario de la partes involucradas y requieren de alguna forma de reconocimiento en los demás Estados ${ }^{35}$.

Y ello es así ante la necesidad imperiosa de dar continuidad a las situaciones jurídicas más allá de las fronteras ${ }^{36}$.

El reconocimiento y la ejecución de los fallos extranjeros requiere a nivel interamericano desarrollos que faciliten una más adecuada circulación internacional, tales:

\subsubsection{Desarrollos en la apreciación del requisito de la jurisdicción internacional del tribunal de origen}

La jurisdicción ${ }^{37}$ plantea en su dimensión internacional dos interrogantes básicas: ¿ante los jueces de qué Estado ha de corresponder incoar una demanda vinculada a un caso privado internacional? y ¿los jueces de qué Estado son los que deben haber dictado un fallo para que éste se encuentre en condiciones que su eficacia sea reconocida en otro? La primera de las cuestiones refiere a la "jurisdicción internacional directa" y a la "jurisdicción internacional indirecta" la segunda ${ }^{38}$. Conceptos vinculados en definitiva a la apreciación de la jurisdicción en dos momentos procesales distintos, al momento de plantearse la demanda o después de dictado el fallo ${ }^{39,40}$.

35 OPERTTI BADÁN, Didier. Reconocimiento y Ejecución de Sentencias Judiciales Extranjeras. Washington: OEA, 1976, p. 2.

36 En conformidad, FERNÁNDEZ ROSAS, José Carlos; SÁNCHEZ LORENZO Sixto. Curso de Derecho Internacional Privado, 2a. ed. Madrid: Ed. Civitas, 1993, p. 103.

37 "Actividad pública realizada por órganos competentes nacionales o internacionales, con las formas requeridas por la ley, en virtud de la cual, por acto de juicio, se aplica el orden jurídico establecido para dirimir conflictos y controversias mediante decisiones eventualmente factibles de ejecución", COUTURE, Eduardo. Vocabulario Jurídico. Montevideo: Biblioteca de Publicaciones Oficiales de la Facultad de Derecho y, Ciencias Sociales de la Universidad de la República, 1960, p. 381. BARRIOS DE ÁNGELIS, Dante. “Teoría General del Proceso - Enseñanza de la misma”. Revista de la Facultad de Derecho y Ciencias Sociales de la Universidad de la República. 1967, vol 18, p.120, la define como "el poder - deber atribuido a órganos estructuralmente imparciales para excluir la insatisfacción jurídica”.

38 BARTIN, Étienne Adolphe. Étude sur les effets internationaux des jugements. Paris: Librairie générale de droit et jurisprudence, 1907. GUTTERIDGE, Harold Cooke. "Les conflits des lois de competence judiciaire dans les actions personnelles". En: Recueil des Cours. La Haye: Académie de Droit International, 1933, vol 44, ${ }^{\circ} 1$, pp. 111-198.

39 OPERTTI BADÁN, Didier. "Algunas Reflexiones Sobre Jurisdicción Internacional y Jurisdicción Exclusiva”. En: OYARZÁBAL, Mario, J.A. (Ed.). Derecho Procesal Internacional. Homenaje al Profesor Dr. Gualberto Lucas Sosa. Buenos Aires: Ed. Ábaco, 2012, p. 178.

40 GOLDSCHMIDT, Werner. "Jurisdicción Internacional Directa e Indirecta". Respuesta al Cuestionario Provisional Acerca de la Jurisdicción Internacional enviado por la Consultoría Jurídica de la Organización de Estados Americanos a los Participantes en la Reunión de Expertos, 9 a 15 de abril. Washington D. C.: 
El análisis de derecho comparado muestra que se acude a distintos criterios con finalidad de constatar la jurisdicción internacional indirecta. Hay regulaciones que remiten a lo que disponga en la materia ya la legislación del Estado donde se invoca el fallo, calificación lex fori, ya del país de origen del mismo, calificación lex causae, y otras, que prevén soluciones específicas sobre jurisdicción internacional referidas al reconocimiento de los fallos extranjeros.

La calificación lex fori en tanto determinación de la jurisdicción internacional del tribunal que dictó el fallo de acuerdo al Derecho del país receptor del mismo, supone una solución fuertemente restrictiva a la circulación internacional de las sentencias ${ }^{41}$ y consecuentemente a la adecuada protección del justiciable. Éste habiendo obtenido una decisión favorable en un juicio tramitado con las garantías del debido proceso, puede luego ver frustrados sus derechos cuando en el Estado donde se pretenda el reconocimiento no sea reconocida en razón de haber sido dictada por tribunal que de acuerdo a las normas de dicho país careciere de jurisdicción para conocer en una causa que al momento de plantearse quizás le era absolutamente ajena.

La Convención Interamericana sobre Eficacia Extraterritorial de las Sentencias y Laudos Arbitrales Extranjeros, artículo 2, literal d, sujeta el requisito de la jurisdicción internacional, no obstante los inconvenientes que presenta la calificación lex fori, a lo que disponga la ley del Estado en el que el fallo deba surtir efectos. Solución que se aparta tanto de su antecedente directo, el Proyecto del Comité Jurídico Interamericano de Convención sobre Eficacia Extraterritorial de las Sentencias y Laudos Arbitrales Extranjeros de 21.1.1977, que en el artículo 1, al enumerar las condiciones requeridas para el reconocimiento consagra en el literal d la calificación lex causae, sin otro límite que la jurisdicción exclusiva del foro requerido ${ }^{42}$, cuanto de los Proyectos presentados por las Delegaciones de Uruguay y México a la Comisión I de la CIDIP II, que tuviera a cargo el tratamiento del tema ${ }^{43}$. El Proyecto uruguayo, de fecha $26.4,1979{ }^{44}$, en el Capítulo Quinto, "De los requisitos

OEA,1980, p. 36, precisa que los conceptos de jurisdicción internacional directa e indirecta responden a distinta teleología, el primero está vinculado a la idea de evitar la denegación de justicia, "ningún litigio debe quedar sin juez competente", en tanto el segundo refiere al reconocimiento de las sentencias extranjeras firmes.

41 En conformidad, ALFONSÍN, Quintín. "La ejecución extraterritorial de las sentencias en materia civil y comercial". Revista de Derecho Público y Privado. 1954, p. 266 ss.; OPERTTI Didier (1984) "La Tercera Conferencia Especializada en Derecho Internacional Privado CIDIP III". Revista Uruguaya de Derecho Procesal, 2, p. 164.

42 OPERTTI BADÁN, Didier, Op. cit., Actas y Documentos de la Segunda Conferencia Especializada sobre Derecho Internacional Privado, p. 271.

43 En relación al Proyecto presentado por Uruguay, ver documento citado en nota 42 pp. 275 - 286; y respecto al presentado por México, ver mismo documento, p. 287 - 295. 44 El Proyecto sigue los lineamientos del Anteproyecto preparado por OPERTTI BADAN, Didier. Exhortos y embargos de bienes extranjeros. Medios de Cooperación Judicial Internacional, Op. cit. 
para el reconocimiento y ejecución de la sentencia extranjera”, exigía dentro de aquellos de naturaleza procesal, artículo 9.1, "provenir de juez o tribunal internacional competente", agregando en el párrafo segundo de dicho numeral: "En caso de existir normas internacionales entre los Estados Partes en materia de competencia se estará a las mismas" y preveía ya en calidad de artículo 21 de la Convención, ya de Protocolo a la misma, regulaciones específicas para la apreciación de la jurisdicción internacional indirecta. El Proyecto mexicano de fecha 27.4.1979, artículo 12, contempló también un tratamiento específico para la jurisdicción internacional.

En razón de lo expuesto nos pronunciamos por superar fórmulas conducentes a considerar que los únicos criterios jurisdiccionales válidos son los consagrados por la ley del foro y analizar soluciones más favorables a la circulación internacional de los fallos, en línea con desarrollos ya existentes a nivel interamericano y regional. Tales, aquellos consagrados por las Convenciones Interamericanas de La Paz de 1984 sobre Competencia en la Esfera Internacional para Eficacia Extraterritorial de las Sentencias Extranjeras, únicamente ratificada por México y Uruguay que, no obstante su limitado ámbito espacial, supuso un valioso intento a nivel continental en el que la jurisdicción internacional indirecta es regulada en base a criterios concretos acordados por los Estados; y de Montevideo de 1989 sobre Obligaciones Alimentarias ${ }^{45}$, artículo 11.a, que condiciona la jurisdicción internacional a que "el juez o autoridad que dictó la sentencia haya tenido competencia en la esfera internacional de conformidad con los artículos 8 y 9 de esta Convención”. Solución lógica, pues si los Estados a través de un texto convencional indican a los magistrados y a las partes cuáles han de ser los jueces competentes para conocer de un caso internacional, corresponde concluir que la sentencia dictada en aplicación de tales disposiciones proviene de jurisdicción intencional competente. En el Mercosur, los Protocolos de Buenos Aires sobre Jurisdicción Internacional en Materia Contractual, Decisión CMC 1/94, artículo 14, "La jurisdicción como requisito para el reconocimiento y ejecución de sentencias y laudos arbitrales" y el no vigente de Santa María sobre Jurisdicción Internacional en Materia de Relaciones de Consumo, Decisión CMC 10/96, artículo 12, "Jurisdicción intencional indirecta", adoptan igual criterio.

En el derecho uruguayo de fuente nacional, el CGP, Libro Segundo, Título X, "Normas Procesales Internacionales", Capítulo IV, "Del Reconocimiento y Ejecución de las Sentencias Extranjeras, artículo 539, "Eficacia de las sentencias", acoge la calificación lex causae, disponiendo en el numeral 1.4, "que el tribunal sentenciante tenga jurisdicción en la esfera internacional para conocer del asunto, de

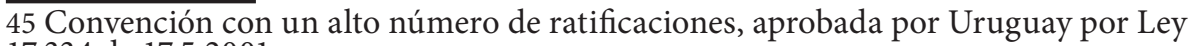
17.334 de 17.5.2001. 
acuerdo con su derecho, excepto que la materia fuere de jurisdicción exclusiva de los tribunales patrios". Jurisdicción que alude a la potestad de los tribunales de un Estado de conocer en relación a un caso o grupo de casos de modo excluyente, de forma tal que si los jueces de otros países conocieran de ellos la consecuencia ha de ser la denegación del reconocimiento de las sentencias dictadas ${ }^{46}$. Frente a interpretaciones que maximizan el alcance de la jurisdicción internacional exclusiva y en definitiva comprometen el derecho del justiciable a acceder a la justicia, entendemos que corresponde una conceptualización cuidadosa que evite una expansión del criterio capaz de transformarlo en serio obstáculo al reconocimiento y circulación internacional, necesaria y de principio, de las decisiones jurisdiccionales extranjeras. Coincidimos con Opertti, en carta con reflexiones referidas al tema que nos enviara en septiembre de 2002, en que la jurisdicción exclusiva debe ser de interpretación estricta y su determinación debe estar "sujeta a criterios de racionalidad que deben tener en cuenta la solución particular del asunto, en consonancia en nuestro DIPr. con la Convención de Normas Generales de DIPr. [CIDIP II, 1979], artículo 9, al consagrar la equidad del caso concreto...", agregando,

Queda de manifiesto que la jurisdicción exclusiva no funciona como si fuera una autorización en blanco para rechazar el fallo extranjero sino como un mecanismo de defensa del orden jurídico nacional, cuando inequívocamente, estamos en presencia de una solución jurisdiccional que le atribuye al Estado uruguayo el conocimiento del caso que se trata.

En esfuerzo por evitar la invocación excesiva de la jurisdicción exclusiva, alguna doctrina ha restringido su invocación a los casos en los que la jurisdicción asumida por los tribunales extranjeros afecte de manera manifiesta el orden público internacional del foro requerido ${ }^{47}$.

El Proyecto uruguayo de Ley General de Derecho Internacional Privado, artículo 60, dispone:

La jurisdicción exclusiva de los tribunales de la República tiene carácter excepcional, debe interpretarse restrictivamente, y carece de fuero de atracción sobre cuestiones que puedan plantearse sobre el mismo asunto. En especial y a modo de ejemplo, se considera materia de jurisdicción

46 En coincidencia, entre otros, GONZALO CAMPOS. Julio Diego. "Competencia judicial internacional de los tribunales españoles". En: Derecho Internacional Privado. Madrid: Universidad Nacional de Educación a Distancia, Facultad de Derecho, 1987, p. 302. BARRIOS DE ÁNGELIS, Dante. Acota al respecto que la condición de foro exclusivo conlleva la de ser un foro único cuantitativamente y excluyente, cualitativamente, de toda otra jurisdicción. BARRIOS DE ÁNGELIS, Dante. El Proceso Civil, Comercial y Penal en América Latina. Buenos Aires: Depalma, 1989, p.210.

47 Tal la posición de GOLDSCHMIT, Werner. Op. cit., p. 103. 
exclusiva de la República las estrictamente concernientes a: derecho reales sobre bienes situados en ella, sistemas registrales organizados por ésta, régimen de protección de la propiedad intelectual e industrial en su territorio y arrendamiento de bienes inmuebles situados en su territorio si fuere de aplicación el régimen estatutario.

Limitación a la jurisdicción exclusiva recibida por recientes textos, entre otros, el Reglamento Europeo (UE) 1215 de 12.12.2012 Relativo a la Competencia Judicial, el Reconocimiento y la Ejecución de Resoluciones Judiciales en Materia Civil y Mercantil, Capítulo III, Sección 6, "Competencias exclusivas", artículo 24; y el Código Civil y Comercial de la República Argentina, Libro Sexto, "De las Disposiciones Comunes a los Derechos Reales y Personales", Título IV, "Disposiciones de derecho internacional privado", Capítulo 2, "Jurisdicción internacional", artículo 2609, "Jurisdicción exclusiva". En consonancia con lo expuesto, los Principios de ASADIP, artículo 3.1, disponen: "Los supuestos en los que se pretenda ejercer jurisdicción exclusiva deben concebirse e interpretarse restrictivamente."

En función de lo expuesto consideramos que en materia de jurisdicción internacional indirecta será deseable concretar a nivel interamericano un Protocolo que ofrezca una regulación específica sobre el tema y sea capaz de lograr una efectiva aprobación por los Estados. Y de no ser ello posible, será necesario concluir en aquellos casos en los que en relación a la materia resuelta por la sentencia extranjera esté vigente entre el Estado de origen de la decisión y aquel en el que se plantee el reconocimiento una regulación convencional sobre la jurisdicción internacional directa, que el fallo cumple con la condición de provenir de tribunal internacionalmente competente ${ }^{48}$; y ante la hipótesis de inexistencia de regulación jurisdiccional convencional, que la jurisdicción del tribunal que dictó la sentencia sea apreciada de acuerdo a su derecho, excepto que la materia fuere de jurisdicción exclusiva del Estado donde el fallo es invocado.

\subsubsection{No revisión del mérito de la causa materia del proceso en que se dictó el fallo}

Si bien la normativa continental sobre eficacia de sentencias extranjeras no ha abordado el tema de modo general, excluyendo sólo de manera expresa la revisión del fondo de la sentencia extranjera en relación al reconocimiento de los fallos extranjeros en materia de

48 Así lo resultante a nivel interamericano, tal como se indicara, del artículo 11.a de la Convención de Montevideo de 1989 sobre Obligaciones Alimentarias y en el Mercosur, del artículo 14 del Protocolo de Buenos Aires sobre Jurisdicción Internacional en Materia Contractual; ídem, lo previsto por el artículo 9, numeral 1, párrafo segundo, del Proyecto uruguayo sobre el tema presentado en ocasión de la CIDIP II. 
alimentos, Convención Interamericana sobre Obligaciones Alimentarias, artículo 13, el rechazo a la revisión del fondo alcanza amplio consenso en derecho comparado, excepto los controles que resulten necesarios para evitar violaciones a los derechos sustantivos fundamentales. La no revisión del fallo extranjero se encuentra expresamente consagrada tanto a nivel de la Conferencia de La Haya de Derecho Internacional Privado, Convenio de 1.2.1971 sobre Reconocimiento y Ejecución de Sentencias Extranjeras en Materia Civil y Comercial, artículo ${ }^{49}$, cuanto en el ámbito europeo desde la Convención de Bruselas de 27.9.1968 Relativa a la Competencia Judicial y la Ejecución de Resoluciones Judiciales en Materia Civil y Mercantil, artículo 34 in fine, hasta el Reglamento (UE) 1215 del 12.12.2012 en la materia, artículo 52. El Derecho uruguayo excluye la revisión del fondo a texto expreso, CGP, artículo, 538.2 ${ }^{50,51}$; y los Principios de ASADIP precisan, Capítulo 7, "Eficacia de decisiones extranjeras", artículo 7.5, "La revisión del fondo de la decisión extranjera, así como la revisión de la determinación de la legislación aplicable al fondo del litigio, son contrarias al derecho de acceso transnacional a la justicia. Se entienden excluidas de esta regla los controles que sean necesarios para evitar violaciones a derechos sustantivos fundamentales".

Consideramos que una nueva regulación interamericana deberá consagrar la no revisión del fondo del fallo foráneo de modo general y expreso, con vistas a facilitar su efectivo reconocimiento internacional.

\subsubsection{Regulación del procedimiento aplicable al control del fallo extranjero}

A diferencia de lo dispuesto por el Tratado de Derecho Procesal Internacional de Montevideo de 1940 que previó procedimientos específicos para la ejecución de sentencias, fallos arbitrales extranjeros y fallos dictados por tribunales internacionales, artículo 7, así como para los casos en que se trate de hacer valer como prueba la autoridad de cosa juzgada de los mismos, artículo 9, la Convención Interamericana de 1979 sobre Eficacia Extraterritorial de la Sentencias y Laudos Arbitrales Extranjeros, artículo 6, remite a lo dispuesto en la materia por el derecho del Estado "en que se solicita su cumplimiento". Solución también adoptada por el Protocolo del Mercosur sobre Cooperación y Asistencia Jurisdiccional Internacional, Capítulo V "Reconocimiento

49 Así como también, entre otros, por el Convenio de 1996 de Protección de Niños, artículo 27. 50 En igual sentido, Convenio entre Uruguay y España de Cooperación Jurídica aprobado por Uruguay por Ley 16.864 de 10.9.1997, artículo 11.1; y Convención entre Uruguay y Francia de Cooperación Judicial en Materia Civil y Comercial, aprobada por Uruguay por Ley 17.110 de 12.5.1999, artículo 20, párrafo segundo.

51 En Francia la revisión de fondo ha sido rechazada a partir del arrêt Munzer, Sentencia de la Corte de Casación de 7.11.1964, "Caso Munzer c/ señora Munzer". 
y Ejecución de Sentencias y Laudos Arbitrales", artículo 24, que, no obstante planteos uruguayos, optó por seguir la fórmula del texto interamericano. Esta remisión a la ley del Estado de invocación del fallo hace posible la aplicación de procedimientos centralizados en tribunales superiores. Solución prevista por las normas de fuente nacional vigentes en varios países, lo que provoca importantes demoras en el reconocimiento de la eficacia del fallo extranjero y con frecuencia, un perjudicial distanciamiento entre el tribunal superior encargado de controlar la sentencia y el lugar donde la misma habrá de surtir efectos.

En razón de lo expuesto nos pronunciamos por la pertinencia de examinar con vistas a un nuevo texto de alcance continental, la posibilidad de consagrar convencionalmente un procedimiento específico para el contralor de los fallos extranjeros, simple y descentralizado, del tipo que hoy acoge la Convención Interamericana de 1989 sobre Obligaciones Alimentarias en el artículo13, solución con antecedentes en disposiciones ya citadas del Tratado de Derecho Procesal Internacional de Montevideo de 1940. Regulación que habrá de facilitar significativamente una más adecuada circulación internacional de las sentencias.

Tales, algunas propuestas que consideramos de interés concretar con miras a una necesaria profundización y actualización del marco convencional vigente a nivel interamericano en materia de cooperación jurisdiccional internacional y reconocimiento de fallos extranjeros.

\section{REFERENCIAS BIBLIOGRÁFICAS}

ALFONSÍN, Quintín. "La ejecución extraterritorial de las sentencias en materia civil y comercial". Revista de Derecho Público y Privado. 1954, p. 266.

ARAÚJO, Nadia de. Direito Internacional Privado - Teoria e Prática Brasileira. $3^{\text {a }}$ ed. Rio de Janeiro: Renovar, 2006.

BARRIOS DE ÁNGELIS, Dante. "Teoría General del Proceso Enseñanza de la misma". Revista de la Facultad de Derecho y Ciencias Sociales de la Universidad de la República. 1967, vol 18, p.120

BARRIOS DE ÁNGELIS, Dante. El Proceso Civil, Comercial y Penal en América Latina. Buenos Aires: Depalma, 1989.

BARTIN, Étienne Adolphe. Étude sur les effets internationaux des jugements. Paris: Librairie générale de droit et jurisprudence, 1907.

GUTTERIDGE, Harold Cooke. "Les conflits des lois de compétence judiciaire dans les actions personnelles". En: Recueil des Cours. La Haye: Académie de Droit International, 1933, vol 44, n 1, p. 111-198.

CALAMANDREI, Piero. Introduzione allo studio sistematico dei provedimento cautelare. Padova: CEDAM, 1936, p.144. 
CAPPELLETTI, Mauro. "Riconoscimento delle sentenze straniere e basi idiologiche della interpretazione giuridica". Boletín Mexicano de Derecho Comparado.1975, vol 3, n²2/23, p.33.

COUTURE, Eduardo. "Los Embargos y el Tratado de Montevideo", nota de jurisprudencia, Revista de Derecho, Jurisprudencia y Administración, 1939, t. XXXVII, p. 247.

COUTURE, Eduardo. Vocabulario Jurídico. Montevideo: Biblioteca de Publicaciones Oficiales de la Facultad de Derecho y Ciencias Sociales de la Universidad de la República, 1960

FAIRÉN GUILLEN, Víctor. Teoría del Ordenamiento Procesal. Madrid: Tecnos, 1969, tomo 2.

FELDSTEIN DE CÁRDENAS, Sara L. Jurisdicción Internacional en Materia Contractual. Buenos Aires: Abeledo Perrot, 1995.

FERNÁNDEZ ARRROYO, Diego P. "Propuestas para una evolución deseable del problema de la competencia judicial internacional". En: OYARZÁBAL, Mario J.A.(Ed.). Derecho procesal transnacional. Homenaje al Profesor Dr. Gualberto Lucas Sosa. Buenos Aires: Ed. Ábaco, 2012.

FERNÁNDEZ ROSAS, José Carlos; SÁNCHEZ LORENZO Sixto. Curso de Derecho Internacional Privado, $2^{\mathrm{a}}$ ed. Madrid: Ed. Civitas, 1993.

GASPAR, Renata Alvarez y KLEIN, Luciane. "La cooperación jurídica internacional en Brasil: especial referencia al diálogo entre el DIPr. autónomo y convencional y los derechos humanos. En: MORENO RODRÍGUEZ, José Antonio y MARQUES, Claudia Lima (ed.). Los servicios en el Derecho Internacional Privado. Jornadas de la ASADIP 2014. Porto Alegre - Asunción: Gráfica e Editora RJR, 2014, p. 191-217.

GOLDSCHMIDT, Werner. "Jurisdicción Internacional Directa e Indirecta”. Respuesta al Cuestionario Provisional Acerca de la Jurisdicción Internacional enviado por la Consultoría Jurídica de la Organización de Estados Americanos a los Participantes en la Reunión de Expertos, 9 a 15 de abril. Washington D. C.: OEA,1980.

GONZALO CAMPOS. Julio Diego. "Competencia judicial internacional de los tribunales españoles”. En: Derecho Internacional Privado. Madrid: Universidad Nacional de Educación a Distancia, Facultad de Derecho, 1987.

MEIJERS, Eduard Mauritz. "L'histoire des principes fondamentaux du droit international privé à partir de Moyen Age spécialement dans l'Europe occidentale. En: Recueil des Cours. Académie de Droit International. 1933, vol 49, III, p. 543-686.

MIAJA DE LA MUELA, Adolfo. Derecho Internacional Privado, 8a ed. Madrid: ATLAS, 1978.

OPERTTI BADÁN, Didier. "Algunas Reflexiones Sobre Jurisdicción Internacional y Jurisdicción Exclusiva". En: OYARZÁBAL, Mario, J.A. (Ed.). Derecho Procesal Internacional. Homenaje al Profesor Dr. Gualberto Lucas Sosa. Buenos Aires: Ed. Âbaco, 2012. 
OPERTTI BADAN, Didier. Exhortos y embargos de bienes extranjeros. Medios de Cooperación Judicial Internacional. Montevideo: Ediciones Jurídicas Amalio Fernández, 1976.

OPERTTI BADÁN, Didier. Exposición en Tercera Sesión. Comisión I - CIDIP II. Actas y Documentos Segunda Conferencia Especializada Interamericana sobre Derecho Internacional Privado. (CIDIP II), vol. II, Washington D.C.: Organización de Estados Americanos, 1980.

OPERTTI BADÁN, Didier. Reconocimiento y Ejecución de Sentencias Judiciales Extranjeras. Washington: OEA, 1976.

SCOTTI, Luciana. "El acceso a la justicia en el Derecho Internacional Privado argentino: nuevas perspectivas en el Código Civil y Comercial de la Nación". En: El acceso a la justicia en el derecho internacional privado - Jornadas de ASADIP (2015, Asunción).

SENTÍS MELENDO, Santiago. "El auxilio entre jueces de distinta jurisdicción”. La Ley. 1956, n 48, p. 70.

TELECHEA BERGMAN, Eduardo. Derecho Internacional Privado. Montevideo: La Ley - Uruguay, 2010.

TELLECHEA BERGMAN, Eduardo. "Desarrollos necesarios en el ámbito interamericano en materia de condición procesal del litigante extranjero y asistencia judicial internacional". En: Liber Amicorum Jürgen Samtleben. Avances del Derecho Internacional Privado en América Latina. Max Plank Institute Fur Ausländisches Und Internationales Privatecht. Montevideo: FCU, 2002.

TELLECHEA BERGMAN, Eduardo. "Dimensión judicial del caso privado internacional. Análisis de la cooperación de mero trámite, probatoria y cautelar en el ámbito interamericano y del Mercosur. En: XXXIV Curso de Derecho Internacional. Washington: Organización de Estados Americanos. Comité Jurídico Interamericano, 2007. p. 221-222.

TELLLECHEA BERGMAN, Eduardo. Derecho Internacional Privado. Montevideo: La Ley, 2010.

VESCOVI, Eduardo. Derecho Procesal Internacional. Uruguay, el MERCOSUR y América. Montevideo: Ediciones IDEA, 2000.

\section{RESUMEN BIOGRÁFICO}

Eduardo Tellechea Bergman es Profesor de Derecho Internacional Privado, Facultad de Derecho de la Universidad de la República. Director, 1985 - 2011, de la Autoridad Central de Cooperación Jurídica Internacional de Uruguay. Delegado a las CIDIP. Presidente, 1992 2011, de la Delegación de Uruguay a la Comisión Técnica de Ministros de Justicia del MERCOSUR. 